\title{
ANTIMICROBIAL SUSCEPTIBILITY BEHAVIOR OF BACTERIAL ISOLATES FROM DIFFERENT CLINICAL SAMPLES AT NISHTAR HOSPITAL MULTAN
}

\author{
Maria Suhail ${ }^{1}$, Nadia Iqbal ${ }^{2}$, Khalid Usman ${ }^{3}$, Farah Deeba ${ }^{2 *}$ \\ ${ }^{1}$ Department of Microbiology and Molecular Genetics, The Women University, Multan, Pakistan \\ ${ }^{2}$ Department of Biochemistry and Biotechnology, The Women University, Multan, Pakistan \\ ${ }^{3}$ Head of Department of Pathology, Nishtar Medical University, Multan, Pakistan
}

\section{Corresponding Author}

Dr. Farah Deeba

Department of Biochemistry and Biotechnology, The Women University, Multan, Pakistan farah.9003@wum.edu.pk

+923325964990

\begin{abstract}
The pathogenic bacteria are getting resistant to antibiotics is significantly growing in the developing countries of the world including Pakistan. The present study was designed to find the basic study on resistance among the patients coming to the Nishtar Hospital, Multan. The study was carried out in the Department of Pathology, Nishtar Hospital, Multan. Total 387 clinical samples of urine, pus, high vaginal swab (HVS) and wound were surveyed for the existence of Gram-positive and Gram-negative pathogens. For these bacterial isolates, antimicrobial susceptibility tests were performed. E. coli was the most prevalent isolates followed by Staphylococcus aureus and Pseudomonas. E. coli was predominated in urine, pus, HVS and wound specimens. Occurance of Staphylococcus aureus, MRSA, Candida and Pseudomonas were $7.9 \%, 3.9 \%, 14.7 \%$ and $1.4 \%$ respectively among the clinical specimens. E. coli shows highest resistance to Linezolid (98.3\%) followed by Ceftrizone (90.8\%), Sulfamethoxazole + Trimethoprim (85\%), Moxifloxacin (82.5\%). High frequency of resistance specifies that there is an unremitting requirement of surveillance of resistance behaviour of antimicrobial agents in our study is to investigate the trend of this problem.
\end{abstract}

\section{Keywords:}

Antibiotic, urine, pus, high vaginal swab, wound 


\section{INTRODUCTION}

Drug resistance in bacteria is becoming a serious problem now days in the whole world. Antibiotic resistance occurs commonly in patients when treated with inordinate or high dosage antimicrobial drugs (1). Bacteria are posing a huge threat to human life by becoming resistant to antibiotics. Cheaper and effective way to control these bacteria is through antibiotics, but resistance to these drugs is extremely threatening in case of antibacterial chemotherapy. The problematic aspect of antibiotics is, once bacteria are exposed to the drug, they try to withstand the antibiotics inhibitory pressure, many of them die but some of them mutate and survive (2). In addition, multidrug-resistant bacteria cannot be treated with available effective drugs (3). In humans, most common type of bacterial infections are the pus, urine infection, UTIs and wounds that occur in both community and hospital settings that have been seen globally $(4,5)$.

The pathogenic cycle involves complex interaction between an organism, the environment and the potential host. The symptoms of bacterial infection in a person depends on the age of the patient and the location, where it causes the disease (6). The change and development of bacterial strain resistance to antibiotic has demanded to change in therapy of antibiotics. One of the main problems, is to fight against antibiotic resistance that involve the use to correct antibiotics (7).

Different combinations of antibiotics are used to overcome the infection caused by resistant bacteria. The main aim of the drug is to inhibit the cell wall, cell membrane, protein and synthesized nucleic acid. The change and development of bacterial strain resistance to antibiotic has demanded to change in therapy of antibiotics. One of the main problems is to fight against antibiotic resistance that involve the use of correct antibiotics (8). The vagina and bladder have natural defense mechanism against migrating E. coli. Diabetic women are significantly more immune to develop vaginitis (both bacterial and fungal) than non-diabetic patient (9). Main objectives of current study are to isolate and characterize the pathogens from different clinical samples collected from Nishtar Hospital, Multan and to determine their susceptibility pattern to different antimicrobial drugs.

\section{MATERIALS AND METHODS}

The samples received from different departments of Nishtar Hospital, Multan during the period of four months (September 2016 to December 2016) were included in current study. These samples were mainly urine, high vaginal swabs (HVS), pus and wound swab. The source 
population comprises male and female gender effected with different infections. Samples were cultured on different media for cultivation and isolation of possible causative pathogens. Urine was cultured on CLED (Cystine Lactose Electrolyte Deficient) agar media, while Pus, HVS and wound swab samples were cultured on blood and MacConkey agar plates under sterile conditions. At aerobic conditions plates were incubated at $37^{\circ} \mathrm{C}$ for 24 hours. After 24 hours, isolated colonies were examined and microorganisms were identified based on their colony morphology, Gram staining and appropriate biochemical testing including Triple Sugar Iron (TSI) test and Simmons Citrate Agar (SCA) test (10). The results were interpreted according to the guidelines of the Clinical and Laboratory Standards Institute (11).

\section{Area, period and study design}

The study was conducted in Multan at Nishtar Medical College and Hospital. Multan is known to be one of the oldest cities of Pakistan. It is also one of the hottest localities of Pakistan, known to be the city of saints. Nishtar Medical College is among the most prestigious educational institutes in Southern Punjab. It is the $3^{\text {rd }}$ oldest medical institution of Pakistan, founded in 1951. Nishtar Medical College is affiliated with Nishtar Hospital, having 1800 beds capacity. There are 29 wards plus an Out Patients Department. There are 15 Operation theaters. The study was conducted between September and December 2016, at Pathology Department of Nishtar Medical College and Hospital.

For determination of antibiotic susceptibility of the bacterial isolates, disc diffusion method was used. Antibiotics discs used for different bacterial species were Augmentin, Amikacin, Cefotaxime, Gentamycin, Ceftazidime and Ceftezole in concentration of $30 \mu \mathrm{g}$ while Ciprofloxacin, Norfloxacin and Clarithromycin as $5 \mu \mathrm{g}$. Other antibiotics were Erythromycin $(101 \mu \mathrm{g})$, Imipenem $(10 \mu \mathrm{g})$, Linezolid $(10 \mu \mathrm{g})$, levofloxacin $(10 \mu \mathrm{g})$, Meropenem $(10 \mu \mathrm{g})$, Moxifloxacin $(5 \mu \mathrm{g})$, Sulzone/Sulbactam/Cefoperazone and $(105 \mu \mathrm{g})$, Piperacillin + Tazobactam $(110 \mu \mathrm{g})$, Vancomycin $(110 \mu \mathrm{g})$, Plates were incubated for 24 hour at $37^{\circ} \mathrm{C}$. After 24 hour of incubation, zones of inhibition were checked and the organisms were classified as sensitive or resistant based on standard criteria. Control strains were used for checking the quality of discs and reagents. The results were expressed in percentages.

\section{RESULTS}

The study was carried out in Department of Pathology, Nishtar Hospital, Multan and total of 387 clinical samples collected. Urine, pus, high vaginal swab (HVS) and wound samples were examined for the presence of Gram-positive and Gram-negative pathogens. 


\section{Bacterial Profile}

In total 387 different clinically tested samples, 204 (52.7\%) organisms were isolated. These include $123(60.29 \%)$ grams negative and 54 (26.47 \%) gram-positive organisms, while 23 $(11.2 \%)$ isolates were identified as contamination along with these pathogens. E. coli with 120 (58.8\%) isolates was the most prevalent gram-negative pathogen followed by 3 (1.4\%) Pseudomonas species. Whereas gram positive isolates included 16 (7.90\%) Staphylococcus aureus, 8(3.9\%) Methylene Resistance Staphylococcus aureus, 30(14.7\%) Candida, 23(11.2\%) contamination along the pathogens and $4(1.9 \%)$ other bacterial species include Streptococcus species, Enterobacter species, Morganella species, Klebsiella species (Table 1).

Table 1: Clinical samples screened and number of isolates obtained

\begin{tabular}{|c|c|c|c|c|c|c|c|}
\hline $\begin{array}{l}\text { Specimen } \\
\text { type }\end{array}$ & E. coli & $\begin{array}{l}\text { Staphylococcus } \\
\text { aureus }\end{array}$ & MRSA & Candida & Pseudomonas & $\begin{array}{lr}\text { Mixed } & \text { growth } \\
\text { along } & \text { with } \\
\text { pathogens } & \\
\end{array}$ & Others* \\
\hline & $(\#=120)$ & $(\#=16)$ & $(\#=8)$ & $(\#=30)$ & $(\#=3)$ & $(\#=23)$ & $(\#=4)$ \\
\hline & $58.80 \%$ & $7.90 \%$ & $3.9 \%$ & $14.7 \%$ & $1.4 \%$ & $11.2 \%$ & $1.9 \%$ \\
\hline Urine & 74 & - & - & 18 & - & 14 & 2 \\
\hline HVS & 17 & 3 & - & - & - & 5 & - \\
\hline Pus & 23 & 13 & 8 & 12 & 2 & 3 & 2 \\
\hline Wound & 6 & - & - & - & 1 & 1 & - \\
\hline \multicolumn{8}{|c|}{ *Others Streptococcous species, entrobacter species, Morganella species, klebsille species } \\
\hline
\end{tabular}

\section{Susceptibility Pattern of Gram Negative Bacteria}

The susceptibility pattern of gram negative bacteria isolated from urine, pus, wound and high vaginal swabs and tested against 19 selected antibiotics (Table 2). E. coli species showed highest resistance to Linezolid (98.33\%) and Ceftriaxone (90.8\%), whereas highest sensitivity to Gentamicin (75\%) and intermediate sensitivity to Meropenem (36.6\%) and Amikacin (36.6\%). Pseudomonas species showed highest resistance (100\%) to Amikacin, Cefotaxime, Ceftezole, Moxifloxacin and Tazobactam + piperacillin and highest sensitivity (100\%) to Imipenem, Levofloxacin, Meropenem and Sulfamethoxazole + Trimethoprim and intermediate sensitivity to Sulzone (33.3\%) (Table 2). Enterobacter species showed highest resistance $(100 \%)$ to Augmentin, Ciprofloxacin, Gentamicin, Imipenem, Levofloxacin, Meropenem, Moxifloxacin, Tazobactam + piperacillin, Sulzone. Highest sensitivity (100\%) to Amikacin, 
Linezolid, Sulfamethoxazole + Trimethoprim and intermediate sensitivity (100\%) were shown to Cefotaxime and Ceftriaxone.

Klebsiella species showed highest resistance (100\%) to Amikacin, Imipenem, Linezolid, Meropenem, Tazobactam + Piperacillin, Sulzone, Sulfamethoxazole + Trimethoprim, while highest sensitivity (100\%) to Augmentin, Cefotaxime, Ceftezole, Ciprofloxacin, Gentamycin, Levofloxacin and intermediate sensitivity to Moxifloxacin (100\%). Morganella species showed highest resistance (100\%) to Augmentin, Amikacin, Cefotaxime, Ciprofloxacin, Gentamycin, linezolid, Moxifloxacin, Tazobactam + Piperacillin, Sulzone, while highest sensitivity (100\%) to Ceftezole, Imipenem, Levofloxacin, Meropenem, Sulfamethoxazole + Trimethoprim (Table 2).

Table 2: Antibiotic Susceptibility pattern of Gram negative bacteria isolated from patients

\begin{tabular}{|c|c|c|c|c|c|c|c|c|c|c|c|c|c|c|c|}
\hline \multirow{2}{*}{$\begin{array}{l}\text { Type and No. of } \\
\text { Isolates }\end{array}$} & \multirow[t]{2}{*}{$\mathbf{R X N}$} & \multicolumn{14}{|c|}{ Antimicrobial Activities (\%) } \\
\hline & & AMC & AK & CTX & CO & CCP & GN & IMI & LNZ & LEV & MEM & MXF & TZP & SUL & SXT \\
\hline \multirow{3}{*}{$\begin{array}{c}\text { E. coli } \\
(\mathrm{n}=120)\end{array}$} & $\mathrm{R}$ & 53.3 & 27.5 & 43.3 & 90.8 & 58.3 & 10 & 19.1 & 98.33 & 70 & - & 82.5 & 38.3 & 34.1 & 85 \\
\hline & $\mathrm{S}$ & 45.8 & 35.8 & 23.3 & 6.66 & 29.1 & 75 & 67.5 & 1.66 & - & 63.3 & 8.33 & 43.3 & 50.8 & - \\
\hline & IS & 0.83 & 36.6 & 33.3 & 2.5 & 12.5 & 15 & 13.3 & - & 30 & 36.6 & 9.16 & 18.3 & 15 & 15 \\
\hline \multirow{3}{*}{$\begin{array}{l}\text { Pseudomonas } \\
\qquad(\mathrm{n}=3)\end{array}$} & $\mathrm{R}$ & 66.6 & 100 & 100 & 100 & 66.6 & 33.3 & - & 33.3 & - & - & 100 & 100 & 66.6 & - \\
\hline & $\mathrm{S}$ & 33.3 & - & - & - & 33.3 & 66.6 & 100 & 66.6 & 100 & 100 & - & - & - & 100 \\
\hline & IS & - & - & - & - & - & - & - & - & - & - & - & - & 33.3 & - \\
\hline \multirow{3}{*}{$\begin{array}{l}\text { Enterobacter } \\
\text { Species }(\mathrm{n}=1)\end{array}$} & $\mathrm{R}$ & 100 & - & - & - & 100 & 100 & 100 & - & 100 & 100 & 100 & 100 & 100 & - \\
\hline & $\mathrm{S}$ & - & 100 & - & - & - & - & - & 100 & - & - & - & - & - & 100 \\
\hline & IS & - & - & 100 & 100 & - & - & - & - & - & - & - & - & - & - \\
\hline \multirow{3}{*}{$\begin{array}{c}\text { Klebsiella } \\
\text { Species }(\mathrm{n}=1)\end{array}$} & $\mathrm{R}$ & - & 100 & - & - & - & - & 100 & 100 & - & 100 & - & 100 & 100 & 100 \\
\hline & $\mathrm{S}$ & 100 & - & 100 & 100 & 100 & 100 & - & - & 100 & - & - & - & - & - \\
\hline & IS & - & - & - & - & - & - & - & - & - & - & 100 & - & - & - \\
\hline \multirow{3}{*}{$\begin{array}{c}\text { Morganella } \\
\text { Species }(\mathrm{n}=1)\end{array}$} & $\mathrm{R}$ & 100 & 100 & 100 & - & 100 & 100 & - & 100 & - & - & 100 & 100 & 100 & - \\
\hline & $\mathrm{S}$ & - & - & - & 100 & - & - & 100 & - & 100 & 100 & - & - & - & 100 \\
\hline & IS & - & - & - & - & - & - & - & - & - & - & - & - & - & - \\
\hline \multirow{3}{*}{ Total $n=126$} & $\mathrm{R}$ & 53.9 & 30.1 & 44.4 & 88.8 & 58.7 & 12.5 & 19.8 & 96 & 67.4 & 1.58 & 82.5 & 41.2 & 36.5 & 81.7 \\
\hline & $\mathrm{S}$ & 45.2 & 34.9 & 23 & 7.93 & 29.3 & 73.8 & 67.4 & 3.96 & 3.96 & 63.4 & 7.93 & 41.2 & 48.4 & 3.9 \\
\hline & IS & 0.79 & 34.9 & 32.55 & 3.17 & 11.9 & 14.2 & 12.6 & - & 28.5 & 34.9 & 9.5 & 17.4 & 15 & 14.2 \\
\hline
\end{tabular}

Key words: RXN; Reaction R; Resistance, S; Sensitive, IS; Intermediate Sensitive, AMC; Augmentin, AK; Amikacin, CTX; Cefotaxime, CO; Ceftezozle, CIP; Ciprofloxacin, GN; Gentamycin, IMI; Imipenem, LNZ; Linezolid, LEV; Levofloxacin, MEM; Meropenem, MXF; Moxifloxacin, TZP; Tazobactam +Piperacillin, SUL; Sulzone, SXT; Sulfamethoxazole + Trimethoprim.

\section{Susceptibility Pattern of Gram Positive Bacteria}

Staphylococcus aureus show highest resistance to Linezolid (100\%), Levofloxacin (100\%) and $93.7 \%$ to Ceftezole, Ciprofloxacin, Gentamycin and highest sensitivity to Imipenem (62.5\%), Meropenem (62.5\%) and intermediate sensitivity to Gentamicin (6.25). Methylene Resistance 
Staphylococcus aureus showed highest resistance (100\%) to Augmentin, Amikacin, Gentamycin, Tazobactam + Piperacillin, Vancomycin and $87.5 \%$ to Cefotaxime and Ciprofloxacin and highest sensitivity (62.5\%) to Ceftezole, Meropenem, Moxifloxacin (Table $3)$.

Streptococcus species showed highest resistance (100\%) to Augmentin, Amikacin, Cefotaxime, Ceftezole, Linezolid, Ciproloxacin, Gentamicin, Imipenem, Meropenem, Moxifloxacin, Tazobactam + Piperacillin, Vancomycin, Sulzone and highest sensitivity to Levofloxacin $(100 \%)$ (Table 3).

Table 3: Antibiotic Susceptibility pattern of Gram positive bacteria isolated from patients

\begin{tabular}{|c|c|c|c|c|c|c|c|c|c|c|c|c|c|c|c|}
\hline \multirow{2}{*}{$\begin{array}{c}\text { Type and No. } \\
\text { of Isolates }\end{array}$} & \multirow[t]{2}{*}{$\mathbf{R X N}$} & \multicolumn{14}{|c|}{ Antimicrobial Activities (\%) } \\
\hline & & AMC & AK & CTX & CO & CCP & GN & IMI & LNZ & LEV & MEM & MXF & TZP & SUL & VA \\
\hline \multirow{3}{*}{$\begin{array}{l}\text { Staph aureus } \\
\qquad(\mathrm{n}=16)\end{array}$} & $\mathrm{R}$ & 43.7 & 75 & 87.5 & 93.7 & 93.7 & 93.7 & 37.5 & 100 & 100 & 37.5 & 100 & 81.2 & 43.7 & 68.7 \\
\hline & S & 56.25 & 25 & 12.5 & 6.25 & 6.25 & - & 62.5 & - & - & 62.5 & - & 18.75 & 56.2 & 31.2 \\
\hline & IS & - & - & - & - & - & 6.25 & - & - & - & - & - & - & - & - \\
\hline \multirow{3}{*}{$M R S A(\mathrm{n}=8)$} & $\mathrm{R}$ & 100 & 100 & 87.5 & 37.5 & 87.5 & 100 & 50 & 62.5 & 75 & 37.5 & 37.5 & 1001 & 50 & 100 \\
\hline & $\mathrm{S}$ & - & - & 12.5 & 62.5 & 12.5 & - & 50 & 37.5 & 25 & 62.5 & 62.5 & - & 50 & - \\
\hline & IS & - & - & - & - & - & - & - & - & - & - & - & - & - & - \\
\hline \multirow{3}{*}{$\begin{array}{l}\text { Streptococcus } \\
\qquad(\mathrm{n}=1)\end{array}$} & $\mathrm{R}$ & 100 & 100 & 100 & 100 & 100 & 100 & 100 & 100 & - & 100 & 100 & 100 & 100 & 100 \\
\hline & S & - & - & - & - & - & - & - & - & 100 & - & - & - & - & - \\
\hline & IS & - & - & - & - & - & - & - & - & - & - & - & - & - & - \\
\hline \multirow{3}{*}{ Total $(n=25)$} & $\mathrm{R}$ & 64 & 84 & 88 & 76 & 88 & 96 & 44 & 84 & 88 & 40 & 76 & 84 & 48 & 76 \\
\hline & $\mathrm{S}$ & 36 & 16 & 12 & 24 & 12 & - & 56 & 16 & 12 & 60 & 24 & 16 & 52 & 24 \\
\hline & IS & & & & & & 4 & & & & & & & & \\
\hline
\end{tabular}

Key words: RXN; Reaction R; Resistance, S; Sensitive, IS; Intermediate Sensitive, AMC; Augmentin, AK; Amikacin, CTX; Cefotaxime, CO; Ceftezole, CIP; Ciprofloxacin, GN; Gentamycin, IMI; Imipenem, LNZ; Linezolid, LEV; Levofloxacin, MEM; Meropenem, MXF; Moxifloxacin, TZP; Tazobactam +Piperacillin, SUL; Sulzone, VA; Vancomycin.

\section{Multi - Drug Resistance Patterns of the Isolates}

Multi-drug resistance (MDR) test was determined by disk diffusion method according to criteria set by CLSI 2011 against different classes of antimicrobials: penicillin (ampicillin), cephalosporin (ceftezole), glycopeptides (vancomycin), aminoglycopeptides (amikacin), fluoroquinolones (ciprofloxacin), folate pathway inhibitors (sulfamethoxazole/trimethoprim), aminoglycosides class (gentamicin), $\beta$-lactam (meropenem), quinolone class (moxifloxacin), extended-spectrum penicillin (Tazobactam + Piperacillin) and carbapenem (Imipenem). Resistance to drugs was found in 204 (52.7\%) of the isolates. One hundred twenty three (123\%) of gram-negative bacteria showed multi drug resistance (ten antimicrobial classes). Similarly, 
fifty-four (54\%) of gram-positive bacteria isolates show multi drug resistance (twelve antimicrobial classes).

\section{DISCUSSION}

Discovery of antibiotics for treatment of bacterial infection was the biggest revolutionary change in the history of medicine. The antibiotic pattern of sensitivity as well as microbial pathogens, may change temporally and dspatially. Present study shows the isolation of large number of broad spectrum microorganisms from urine, pus, wound and HVS samples. E. coli, an opportunistic bacterium, and fecal coliform was isolated from urine, pus and HVS samples. Isolation of E.coli from these samples including many reasons depicts the poor hygienic conditions of the population. Hygienic problem is seen more in rural areas because of lack of cleanliness, as these areas are usually deprived of proper waste managements and no proper sanitary system, leadings to the spread of E. coli infection which can spread from person to person. Resistance to drug has many reasons, like there is a complete course of drug for any infection, many patients stop taking medicine on the third or fourth day when they feel relief, and when they get again infected that bacteria is now resistant to that drug. Another reason is that they have been treated by other doctor, and frequent change in doctor and change in medicine make bacteria resistant to that drug. Current study shows lowest degree of bacterial resistance to drug, and highest degree of sensitivity. Isolated colonies were plated with antimicrobial disc to check their susceptibility pattern. Susceptibility pattern is done to see which drug is more effective against any bacteria. If bacteria are resistant to the drug its means that drug is unable to kill bacteria, that is why susceptibility pattern is checked that which drug for combination of drug is more effective against any infection. The study shows higher degree of sensitive of E. coli to Sulzone/Sulbactum $62.7 \%$. Previously studies have been conducted on susceptibility pattern. Various studies were conducted on broad spectrum antibiotics and development of resistance in Non-targeted bacteria (2). Bacteria were screened against tetracycline antibiotics. Total of 157 E. coli were isolated, out of which 133 showed resistant. Our results were more sensitive than resistant to drug. Out of 73 isolates, 64 were resistant of tetracycline and 9 were found susceptible. Our result is more sensitive to sulzone/sulbactum may be because the person is being treated with drug previously. This may be due to change in environment. Change in result is due to change in genetic makeup of people. 
Susceptibility behavior of E. coli; prevalence of multidrug resistant isolates and extended spectrum $\beta$-lactamase phenotype was studied by many workers (12). Out of 378 total sample, 277 were female and 151 were male in study population. Their study shows most of bacterial isolates were resistant to ampicillin (76\% and $72 \%$ respectively). Our results show no degree of resistance to ampicillin. This may be due to reason that the patient is not being treated with this drug. Antibiotic susceptibility pattern of bacterial isolates showed that predominantly gram negative bacteria exhibited high resistance to all group of antibiotics (1). Total of 925 different clinical samples, 379 (40.9\%) organisms were isolated. These included $118(31.1 \%)$ Gram positive and 261 (68.9\%) Gram negative isolates. Staphylococcus aureus 88 (23.2\%), the most prevalent gram-positive pathogen and gram-negative isolates included E. coli 121 (31.9\%), Klebsiella 62 (16.4\%) and Pseudomonas species 59 (15.6\%). The study showed a very high percentage of resistance among Gram negative organisms to all generations of cephalosporin antibiotics and $\mathrm{H}$ lactam/H lactamase inhibitors. In our study, highest degree of sensitivity was shown among imipenem $76.6 \%$, meropenem $71.5 \%$, and CSF $106.6 \%$.

Antimicrobial susceptibility pattern of bacterial isolates from wound infection and their sensitivity to alternative topical agents in South-West Ethiopia (13). The study shows that 145 bacterial isolates from 150 clinical specimens showing high isolation rate (87.3\%). The prevalent bacteria isolated from the infected wounds were Staphylococcus aureus 47 (32.4\%) after that E. coli 29 about 20\%, various Proteus species 23 (16\%), Coagulase negative Staphylococci 21 (14.5\%), Pseudomonas aeruginosa 11 (8\%) and Klebsiella pneumoniae 14 $(10 \%)$. These bacterial species exhibited high degree of resistance to various antibiotics including penicillin, ampicillin, cephalothin and tetracycline. Present study represented predominant sensitivity as compare to resistance. Results of current study exhibited reduced of resistance to antibiotic moxifloxacin which was $3.33 \%$. This alteration may be due to reason that there may be mutation in genetic material as every person has diverse genetic makeup where these bacteria live. Some persons are less resistant to bacterial or any other infection and many be attacked by disease with a single touch to infected thing.

\section{CONCLUSION}

Our results show that $E$. coli was most prevalent microorganism isolated from Urine, pus, HVS and wound sample also by Pseudomonas as well as Staphylococcus aureus. These isolates showed highest resistance to Linezolid and Ceftriaxone, Sulfamethoxazole + Trimethoprim, Amikacin, Imipenem, and Moxifloxacin. Such a revelation of higher antibiotic resistance 
demands for appropriate and low dosage of antibiotic in accordance with the recent antibiotic prescribing policy in Pakistan.

\section{REFERENCES}

1. Javeed, I. J., Hafeez, R., Anwar, M. S. 2011. Antibiotic Susceptibility Pattern of Bacterial Isolates from Patients Admitted to a Teritary Care Hospital in Lahore. Biomedica, 27 :19-23.

2. Hussain, T., Jamal, M., Nighat, F., Andleeb, S. 2014. Broad spectrum antibiotics and resistance in non-target bacteria: An example from tetracycline. J Pure Appl Microbiol., 8: 2667-2671.

3. Alawi, M. M., Darwesh, B. M. 2016. A stepwise introduction of a successful antimicrobial stewardship program: Experience from a tertiary care university hospital in Western, Saudi Arabia. Saudi Med. J. 37(12):1350-1358.

4. Hryniewicz, K., Szczypa, K., Sulikowska, A., Jankowski, K., Betlejewska, K., Hryniewicz, W. 2001. Antibiotic susceptibility of bacterial strains isolated from urinary tract infections in Poland. J. Antimicrob Chemother., 47: 773-780.

5. Prestinaci, F., Pezzotti, P., Pantosti, A. 2015. Antimicrobial resistance: a global multifaceted phenomenon. Pathog Glob Health, 109(7):309-318

6. Geoffrey, A.O., Scolastica, C.K., Joan, C.C., Ongechi, D.R., Benard, M.M., Godfrey, O.M., Eliakim, M.M., Isabella, J.K. 2013. Isolation, identification and characterization of urinary tract infectious bacteria and the effect of different antibiotics. J Nat Sci Res., 3: 150-159.

7. Nicoletti, G., Schito, G., Fadda, G. I. O. V. A. N. N. I., Boros, S., Nicolosi, D., Marchese, A., Spanu, T., Pantosti, A., Monaco, M., Rezza, G., Cassone, A., Garaci, E. 2006. Bacterial isolates from severe infections and their antibiotic susceptibility patterns in Italy: a nationwide study in the hospital setting. J Chemotherap., 18: 589-602.

8. Rahman, M. U., Cantwell, R., Johnson, C. C., Hodinka, R. L., Schumacher, H. R., \& Hudson, A. P. 1992. Inapparent genital infection with Chlamydia trachomatis and its potential role in the genesis of Reiters syndrome. DNA Cell Biol., 11(3), 215-219.

9. Cappuccino, J. G and Sherman, N. 2008. Microbiology; a laboratory manual (VOL 8) Pearson/Benjamin Cummings, Singapore.

10. Acharya, May 17, 2013. http://microbeonline.com/citrate-utilization-test-principleprocedure-expected-results-and-positive-organisms/(accessed 14 Dec 2016). 
11. Clinical and Laboratory Standards Institute. 2010. Performance standards for antimicrobial susceptibility testing: 20th informational supplement (June 2010 update), M100-S20-U. Clinical and Laboratory Standards Institute, Wayne, PA.

12. Iqbal, M., Patel I.K., Shah, S.H., Ain Q., Barney, N., Kiani, Q, et al., 2002. Susceptibility patterns of Escherichia coli: prevalence of multidrug-resistant isolates and extended spectrum beta-lactamase phenotype. J Pak Med Assoc., 52:407-411.

13. Mama, M., Abdissa, A., Sewunet, T. 2014. Antimicrobial susceptibility pattern of bacterial isolates from wound infection and their sensitivity to alternative topical agents at Jimma University Specialized Hospital, South-West Ethiopia. Ann Clin Microbiol Antimicrob., 13: 110. 